\title{
Coronary-Subclavian Steal Syndrome: An Infrequent Cause of Ischemia Post Coronary Artery Bypass Graft Surgery
}

\author{
Luis Arboine ${ }^{\mathrm{a}, \mathrm{b}}$, Juan M. Palacios ${ }^{\mathrm{a}}$, Oddir Jauregui ${ }^{\mathrm{a}}$, Ramon De la Cruz ${ }^{\mathrm{a}}$, Eduardo Galvan ${ }^{\mathrm{a}}$, \\ Ulises Lopez ${ }^{\mathrm{a}}$, Jorge Garcia ${ }^{\mathrm{a}}$, Enrique Cruz ${ }^{\mathrm{a}}$, Raul Ontiveros ${ }^{\mathrm{a}}$
}

\begin{abstract}
Coronary-subclavian steal syndrome (CSSS) is a rare complication of coronary artery bypass graft (CABG) surgery. We describe the case of a 72-year-old male patient who presented with chest pain and hypotension $24 \mathrm{~h}$ after CABG surgery. The angiography showed reduced blood flow to the left anterior descending (LAD) artery and severe left proximal subclavian artery stenosis (SAS). The patient underwent successful left subclavian artery stenting. All patients considered for CABG surgery should be screened with bilateral non-invasive brachial blood pressure prior to surgical referral and differences greater than $10 \mathrm{~mm} \mathrm{Hg}$ between arms warrant additional testing.
\end{abstract}

Keywords: Coronary-subclavian steal syndrome; Ischemia; Coronary artery bypass graft surgery

\section{Introduction}

An infrequently recognized cause of myocardial ischemia following coronary artery bypass graft $(\mathrm{CABG})$ surgery using left internal mammary artery (LIMA) is the presence of proximal left subclavian artery stenosis (SAS), which can result in coronary-subclavian steal syndrome (CSSS). Prevalence varies across studies, ranging from $0.2 \%$ to $6.8 \%$ and it may be underestimated since angiographic assessment is not routinely performed in the pre-operative setting in many centers and clinical signs among patients may be absent $[1,2]$.

The clinical features of this syndrome may be recognized in the perioperative period or several years after the surgery. The classic signs are typical angina related to physical activity involving the left upper extremity, acute coronary syndromes and symptoms of vertebrobasilar insufficiency [3].

Manuscript submitted July 9, 2017, accepted July 24, 2017

aDivision of Cardiology, Department of Interventional Cardiology, Unidad Medica de Alta Especialidad, Hospital de Cardiologia No. 34, Instituto Mexicano del Seguro Social, Monterrey, Nuevo Leon, Mexico

${ }^{\mathrm{b}}$ Corresponding Author: Luis Alberto Arboine Aguirre, Valois \# 708, Nexxus Residencial Sector Cristal, General Escobedo, Nuevo Leon, CP 66055, Mexico. Email: luisarboine1986@gmail.com

doi: https://doi.org/10.14740/jmc2875w

\section{Case Report}

A 72-year-old male with a history of smoking and systemic hypertension presented with exercise-induced angina. On physical examination, the patient had a blood pressure of $110 / 70$ $\mathrm{mm} \mathrm{Hg}$ and a resting heart rate of $70 \mathrm{bpm}$. There were no relevant signs on examination. Echocardiogram showed normal left ventricular ejection fraction with no significant valvular abnormalities. Exercise stress revealed high-risk findings and coronary angiography showed severe distal left main disease (Fig. 1). The patient underwent CABG with LIMA graft to left anterior descending (LAD) coronary artery and saphenous vein graft to the first diagonal artery without complications.

Twenty-four hours after CABG, the patient presented angina, hypoxemia, hemodynamic instability with blood pressure of 70/40 $\mathrm{mm} \mathrm{Hg}$ and the electrocardiogram showed ST-elevation in precordial leads. The patient was started on inotropic drugs and taken immediately to the catheterization laboratory demonstrating reduced blood flow to the LAD, evidence of retrograde filling of the LIMA from the LAD (Fig. 2) and severe left proximal SAS (Fig. 3a).

SAS was successfully treated with dilatation and placement of a $6.0 \times 59 \mathrm{~mm}$ self-expanding biliary stent (Boston Scientific

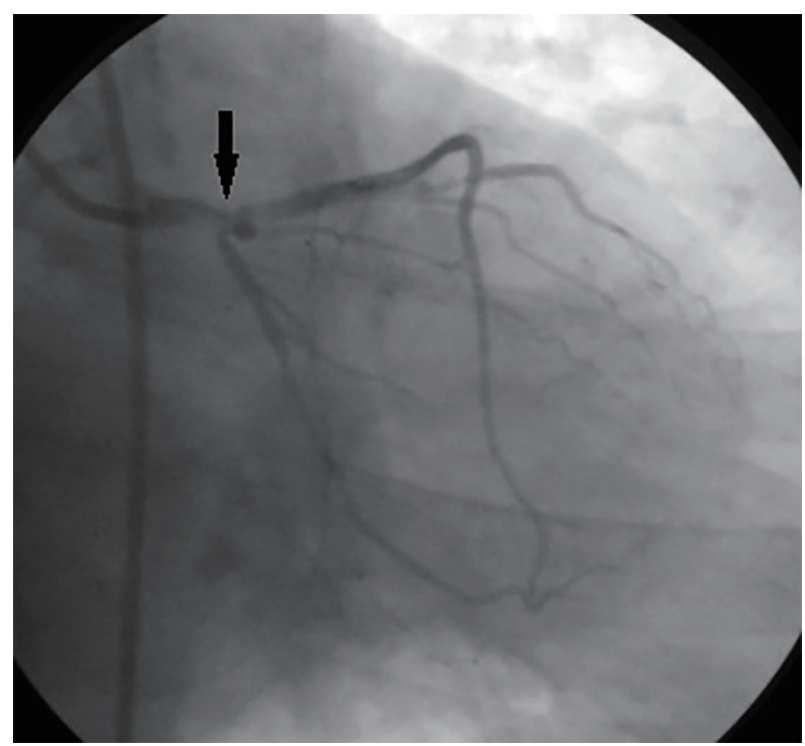

Figure 1. Selective angiogram of the left coronary artery showing left main stenosis (arrow). 


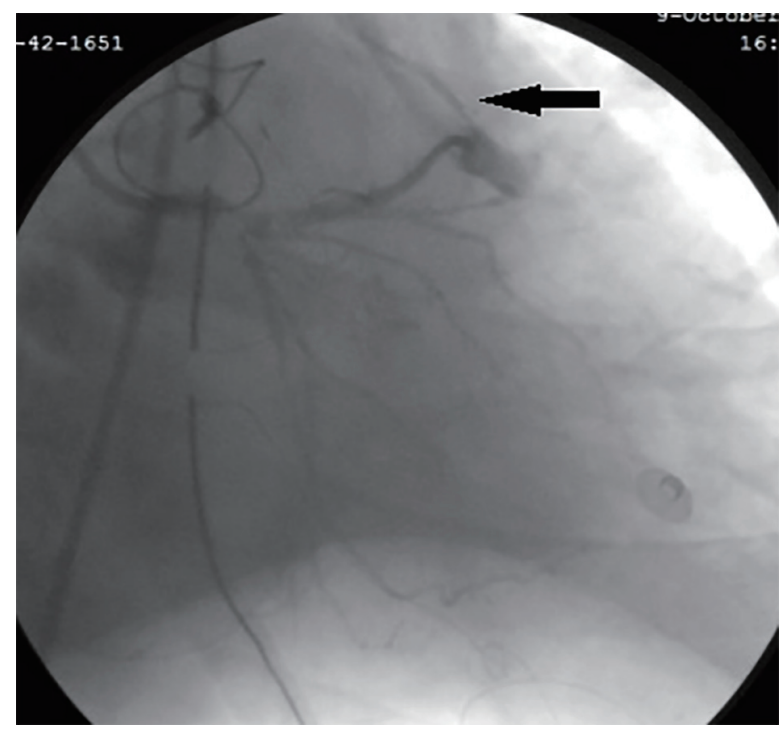

Figure 2. Left internal mammary artery to left anterior descending graft with retrograde blood flow (arrow).

Corp., Natick, MA, USA) demonstrating recovery and normalization of flow towards the LIMA (Fig. 3b). After subclavian artery intervention, his chest pain and blood pressure improved. The patient was discharged home 14 days after CABG. At 12-months follow-up, the patient continues to do well with no recurrence of his angina symptoms.

\section{Discussion}

The LIMA is currently used in most CABG surgeries due to excellent long-term patency [4]. Since the first description of this entity by Harjola and Valle [5], there have been isolated case reports of CSSS. Atherosclerosis is the most common cause of stenosis (95-97\%), although arteriovenous fistula, Takayasu's arteritis, congenital aortic abnormalities, and thoracic outlet syndrome have also been described as possible causes $[2,6]$.

The presence of symptoms within the first 2 years of surgery indicates that the patient had already a relevant stenosis at the moment of CABG [7]. The clinical diagnosis is based on history and physical examination. A difference in blood pressure readings between arms of more than $10 \mathrm{~mm} \mathrm{Hg}$ suggests the diagnosis. Once the clinical syndrome is suspected, an image-based approach must follow using Doppler ultrasound, computed tomography angiography, magnetic resonance angiography and arteriography [8]. The current treatment options for this syndrome include surgical or endovascular revascularization. The endovascular approach with percutaneous transluminal angioplasty (PTA) and peripheral stenting has been considered first-line treatment for SAS and has many advantages including a minimally invasive approach, shorter hospital stay, less morbidity, and avoidance of general anesthesia compared to surgical bypass techniques. Initial success rates of PTA/stenting for SAS have been $100 \%$ in multiple studies compared to more variable outcomes with subclavian artery occlusions. Overall, long-term patency is excellent, with nearly $90 \%$ of patients free of restenosis at 4 years. Surgical methods to manage SAS include carotid-subclavian, carotidaxillary, axillo-axillary, and aorta-subclavian bypasses, as well as transposition of the internal mammary artery. These surgical procedures are relatively high risk but may be the only option for revascularization in patients with a completely occluded subclavian artery. Surgical bypass has been the preferred option in circumstances where length of the lesion is $>5 \mathrm{~cm}$, where there is severe calcification and complete occlusion near the ostium of the vertebral artery $[9,10]$.

Percutaneous intervention on the subclavian artery prior to bypass grafting appears to be an attractive approach and is becoming the most popular in patients not requiring emergent
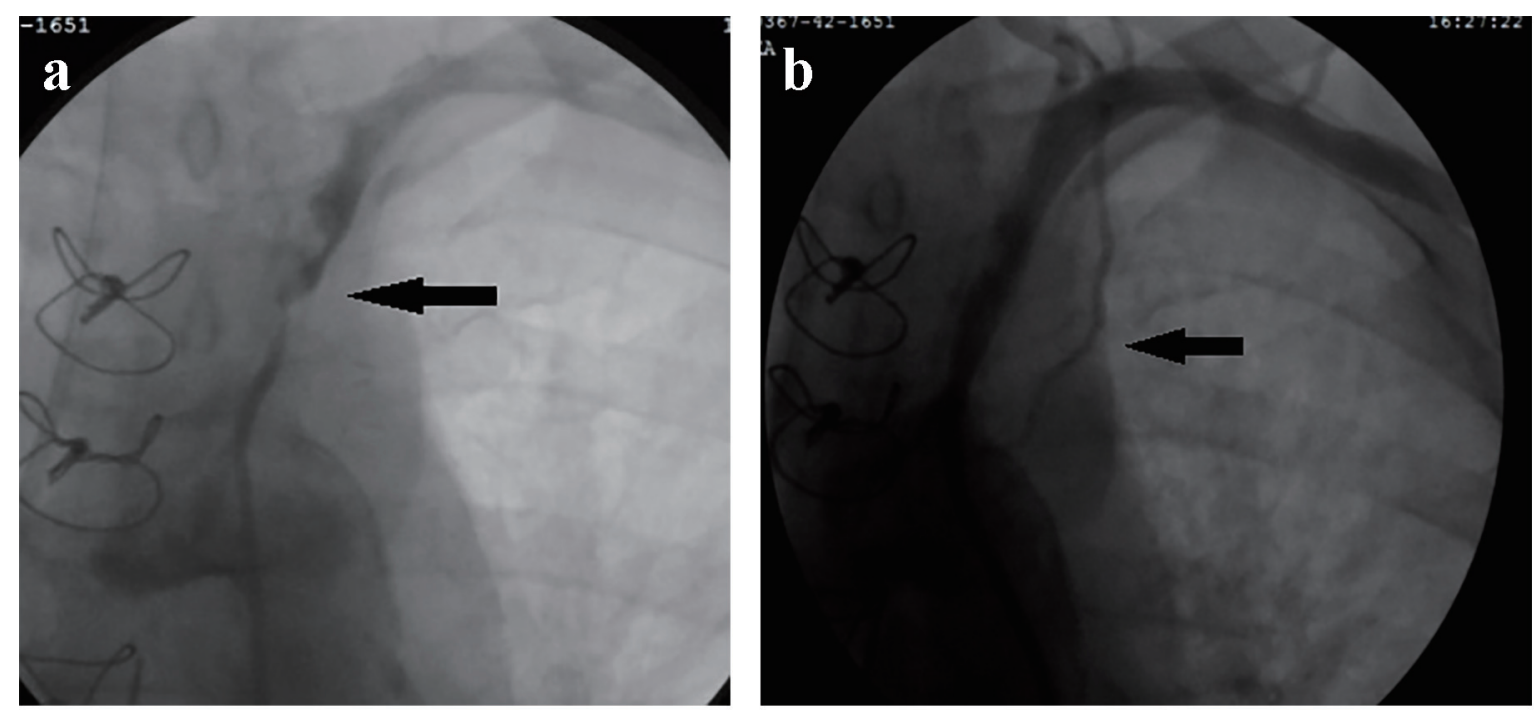

Figure 3. Selective left subclavian angiography demonstrating (a) a severe stenotic lesion (arrow) proximal to the origin of the left internal mammary artery (LIMA), and (b) correction of stenosis after dilatation and stenting. Angiographic LIMA flow was markedly improved (arrow). 
CABG. Although there are no published data with regard to timing of CABG after SAS stenting, aspirin should be given after stenting and can be continued through $\mathrm{CABG}$. The role of clopidogrel in subclavian artery stenting has not been studied. Given the large caliber of the subclavian artery and low thrombosis rates, CABG can theoretically be performed safely soon after intervention, even within the first few $[4,11]$.

\section{Conclusion}

CSSS should be considered in the differential diagnosis of patients presenting with angina or acute coronary syndrome after CABG. A careful pre-operative assessment, with a detailed history and physical examination, looking for signs or symptoms of arm claudication, as well as blood pressure measurement in both arms will help diagnose this entity before $\mathrm{CABG}$ surgery is performed. If a clinical finding suggests stenosis of the left subclavian artery, a selective angiography should be performed during the routine coronary angiography.

\section{Grant Support}

None.

\section{Conflicts of Interest}

None.

\section{References}

1. Martinez-Dolz L, Sancheza E, Almenar L, Arnau MA, Osa A, Palencia M. [Refractory angina caused by subclavian-coronary steal syndrome treated with angioplasty and stent]. Rev Esp Cardiol. 2001;54(7):920-923.

2. Seung-Ah Lee, Ji-Hyun Kim, Hyo-Sun Shin, Hee-Sun Lee, Hong-mi Choi, Hae-Young Lee. Patent coronary artery bypass graft is not sufficient for myocardial perfusion-non-ST elevation myocardial infarction caused by critical subclavian artery stenosis. J Lipid Atheroscler 2014;3(1):39-42.

3. Alvarez J, Urda T, Mancha I, Martinez JL, Gutierrez J, Such M, Vivancos R, et al. [Angina caused by subclavian-coronary steal in patients revascularized with internal mammary artery]. Rev Esp Cardiol. 1998;51(9):772-775.

4. Prasad A, Prasad A, Varghese I, Roesle M, Banerjee S, Brilakis ES. Prevalence and treatment of proximal left subclavian artery stenosis in patients referred for coronary artery bypass surgery. Int J Cardiol. 2009;133(1):109111.

5. Harjola PT, Valle M. The importance of aortic arch or subclavian angiography before coronary reconstruction. Chest. 1974;66(4):436-438.

6. Chokyu I, Terada T, Matsuda Y, Okumura H, Shintani A, Nakamura Y, Ohura Y, et al. Stenting for left subclavian artery stenosis before and after coronary artery bypass grafting using the internal mammary artery: a report of three cases. Interv Neuroradiol. 2008;14(2):209-214.

7. Berenguer A, Marin F, Espana F, Ruiz J, Navarrete C, Mainar V. Angioplastia transluminal percutanea en pacientes con estenosis de la arteria subclavia e injertos de arteria mamaria. Rev Esp Cardiol. 2002;55(5):537-540.

8. Miranda G, Zarca M, Mora C, Sanchez M, Ferreras I, Rivera F. Estenosis de arteria subclavia: importancia de medir la presion arterial en ambas extremidades y su asociacion con el riesgo cardiovascular. Hipertens Riesgo Vasc. 2014;31(1):23-26.

9. Younus U, Abbott B, Narasimha D, Page BJ. Coronary subclavian steal syndrome: an unusual cause of Angina in a post-CABG patient. Case Rep Cardiol. 2014;2014:769273.

10. Sintek M, Coverstone E, Singh J. Coronary subclavian steal syndrome. Curr Opin Cardiol. 2014;29(6):506-513.

11. Rogers JH, Calhoun RF, 2nd. Diagnosis and management of subclavian artery stenosis prior to coronary artery bypass grafting in the current era. J Card Surg. 2007;22(1):20-25. 